\title{
Effect of ceramic powder addition on the insulating properties of polymer layer prepared by dip coating method
}

\author{
S. Y. Kim ${ }^{\text {a }}$ J. B. Lee ${ }^{\text {, }}$ B. G. Kwon ${ }^{a}$, and G. W. Hong*, a \\ ${ }^{a}$ Korea Polytechnic University, Gyeonggi-do, Korea \\ ${ }^{\mathrm{b}}$ Green Resource Co., Ltd., Gyeonggi-do, Korea
}

(Received 6 September 2013; revised or reviewed 11 December 2013; accepted 12 December 2013)

\begin{abstract}
The mechanical, electrical and thermal characteristics of insulating materials may significantly affect the performance and reliability of electrical devices using superconductors. General method to provide insulating layer between coated conductors is wrapping coated conductor with Kapton tape. But uniform and compact wrapping without failure or delamination in whole coverage for long length conductor is not a simple task and need careful control. Coating of insulating layer directly on coated conductor is desirable for providing compact insulating layer rather than wrapping insulating layers around conductor. Ceramic added polymer has been widely used as an insulating material for electric machine because of its good electrical insulating properties as well as excellent heat resistance and fairy good mechanical properties. The insulating layer of coated conductor should have high breakdown voltage and possesses suitable mechanical strength and maintain adhesiveness at the cryogenic temperature where it is used and withstand stress from thermal cycling. The insulating and mechanical properties of polymer can be improved by adding functional filler. In this study, insulating layer has been made by adding ceramic particles such as $\mathrm{SiO}_{2}$ to a polymer resin. The size, amount and morphology of added ceramic powder was controlled and their effect on dielectric property of the final composite was measured and discussed for optimum composite fabrication.
\end{abstract}

Keywords: coated conductor, filler added polymer, insulation, breakdown voltage

\section{INTRODUCTION}

초전도 재료는 일반도체와 달리 저항이 없어서 대전류를 손실 없이 전달시킬 수 있으므로 선재의 형태로 가공하여 송전선이나, 변압기, 발전기 및 전력 저장장치와 같은 전력기기의 효율을 극대화 시킬 수 있는 재료로서 널리 활용되고 있다. 모든 초전도 전력기기에 필수적으로 사용되는 초전도 선재는 전기적, 열적, 기계적 특성과 경제성 등이 고려되어야 한다. 특히 초전도 기기의 응용 환경인 높은 외부자기장과 초전도 현상이 유지되는 초전도 임계전이온도 이하의 극저온 환경에서 높은 통전전류 (Ic)와 임계전류밀도 $(\mathrm{Jc})$ 그리고 기기 운전 및 제작의 편리를 위한 높은 기계적 강도와 유연성 등과 함께 교류 전력기기인 경우는 낮은 교류손실 특성도 매우 중요하다 $[1,2]$. 이와 함께 대형 전력기기의 경우 초고압에 의한 절연파괴로 많은 전류가 누설되어 초전도 전력기기와 주변 기기가 손상되지 않도록 안정성도 확보해야 하기 때문에 극저온상태에서의 절연강도 특성, 부분방전 특성 등도 기기의 성능을 결정할 때 매우 중요한 요소로 작용한다 $[3,4]$.

일반전선의 경우는 사용환경에 제약이 적으므로 다양한 원료와 공정으로 절연층을 만들 수 있는데 절연특성이 우수하고 제조 비용이 저렴한 고분자 절연층을 코팅하는 방법이 많이 사용되고 있다[5]. 전기 절연재료는 높은 전계 중에 놓여지게 되면 전기적 stress 외에 자외선, 수분의 침투, 열, 방사선 등이 더해져서 사용시간이 길어짐에 따라

* Corresponding author: gwhong@kpu.ac.kr
절연특성이 저하된다. 경량성, 성형성 및 내부식성이 우수한 고분자를 일반전선의 절연층 소재로 사용하고 있지만 고분자 소재는 열전도도가 낮기 때문에 열전달에 의해 도체를 임계전이온도 이하의 운전온도로 냉각시켜야 하는 초전도 선재에서는 그 자체로는 사용에 제약이 있다.

초전도 전력기기는 초전도 현상이 일어나는 극저온을 유지함과 동시에 기기의 경제성을 확보하기 위해 고전압 대용량 전류조건에서 주로 사용된다. 현재 고온초전도 케이블의 전기절연을 위해서는 냉각에 의한 수축 및 열적인 손실을 줄일 수 있는 지절연 방식을 주로 사용하고 있다. 이는 내열성과 전기절연성이 우수한 고분자 절연 테이프를 적층하여 절연을 하는 방법으로 현재 기술상으로 적용 가능성이 가장 높은 절연방식이다. 하지만 박리 없이 균일하게 테이프를 감는 것은 어렵고, 절연지를 여러 겹 적층하게 되면 선재의 두께가 두꺼워지므로 공학적 임계전류밀도 $\left(\mathrm{J}_{\mathrm{e}}\right)$ 가 줄어들게 되고 선재를 사용한 기기의 부피가 커지게 되는 문제가 발생한다. 본 연구에서는 이런 문제점을 보완하기 위해, 선재 표면을 일반전선처럼 폴리머용액으로 코팅하여 절연층을 제조하는 방법에 대하여 연구하였다. 선재 표면에 폴리머 용액을 얇은 두께로 균일하게 코팅하여 표면 전체를 보호하는 절연층을 제작하게 되면 초전도 선재의 전류밀도 $\left(\mathrm{J}_{\mathrm{e}}\right)$ 를 높여 전력기기의 효율을 더욱 높일 수 있다. 초전도 전력기기는 특성상 극저온에서 운전되므로 수명기간 동안 기기의 온도가 크게 변화할 수 있으며 이에 따라 열팽창과 수축이 반복되어 절연층과 선재의 금속층의 열팽창계수가 크게 다르거나 두 층 사이의 접합특성이 부족하면 분리가 일어날 
수 있으므로 일반전선과는 달리 열적 특성과 유연성 등이 선재와 비슷한 폴리머를 사용해야 한다. 또한 초전도 전력기기의 특성상 일반전력기기보다 전류가 크고, 전압이 높으므로 일반 전선용 폴리머보다 유전상수가 높은 재료가 필요하다.

본 연구에서는 폴리머의 절연특성과 열적특성 등을 향상시키기 위하여 내구성이 좋은 폴리머를 선택한 후 폴리머에 유전상수가 높은 세라믹분말을 첨가하여 폴리머-세라믹 복합체를 만들어 초전도선재용 절연층으로 사용하고자 하였다. 높은 유전상수를 갖는 세라믹 입자와 고분자재료를 혼합하여 만든 폴리머-세라믹 복합체는 유전특성을 조절하기 쉽고, 가벼우며, 저온에서도 코팅공정이 가능하다는 장점이 있어서 많은 연구가 진행되어 왔다[6-8]. 복합체의 유전 특성의 차이는 사용된 고분자 및 세라믹 첨가물 각각의 기본적인 물성 또는 분산 상태에 따라 달라지게 된다. 폴리머에 높은 유전상수를 갖는 세라믹 분말의 함량을 증가시키면 복합체의 유전율은 증가하고 유전손실은 감소하게 된다. 고분자재료는 낮은 온도에서 금속재질의 초전도 선재 표면에 고정시키는 유기고착제(organic binder)의 역할을 하여, 경화되면서 높은 유전상수를 갖는 세라믹 입자를 금속표면에 기계적으로 지지해주고, 세라믹 입자는 높은 유전상수를 제공한다 $[9,10]$. 절연을 위해 사용하는 여러 가지 폴리머 중에서 열 경화성 수지는 상온 또는 낮은 온도의 가열에 의해 수지 전체가 경화되며, 일단 경화된 후에는 화학적으로는 안정하고 우수한 전기적 및 기계적 특성을 보이는 장점이 있다. 또한 경화 전에는 점도와 유동성을 조절할 수 있어서 충진제의 종류와 첨가량에 따라 최적의 접합특성을 보이도록 폴리머의 특성을 조절할 수 있기 때문에 폴리머 단독 사용에 비해 많은 장점이 있다. 본 연구는 이렇게 세라믹 재료와 고분자 재료가 갖는 각각의 단점을 보완하고 서로의 장점을 살려 우수한 유전특성을 얻기 위해 수행한 일차실험결과이다. 폴리머 용액에 세라믹분말을 균일하게 분산시켜 제조한 코팅용 전구용액으로 안정한 절연층을 만들었으며 이 때 세라믹 분말의 크기와 첨가량이 절연내력 및 안정성에 미치는 영향을 관찰하여 최적의 절연층을 제조하기 위한 기초자료를 제공하고자 하였다.

\section{EXPERIMENTS}

Fig.1은 절연층 증착용 폴리머 전구용액의 제조, 코팅과 코 팅 후 열처리, 그리고 특성측정 과정을 표현한 절차도이다.

실험에 사용된 폴리머는 한국다우코닝에서 생산하는 PDMS (Polydimethylsiloxane, Sylgard 184A)를 사용하 였고 코팅용액의 유전율을 높이기 위한 세라믹소재는 $\mathrm{SiO}_{2}$ 분말을 선택하였다. 얇으면서도 균일한 코팅을 위한 점도조 절 용매로 $\mathrm{MEK}$ (Methyl ethyl ketone)를 첨가하여 $\mathrm{PDMS}$ 의 높은 점도를 코팅에 적당한 점도로 조절하였다. 또 한 절연특성을 테스트하기 위해 SUS테이프 위에 딥코팅 방 법으로 코팅하여 증착조건에 따라 특성을 비교하였다.코팅 용액의 제작은 유기용매 (MEK)에 PDMS를 $45 \%$ 의 농도로 넣고 교반기로 혼합하여 용액의 전체적인 점도를 낮추고 점 도가 낮아진 폴리머 용액에 세라믹분말 $\left(\mathrm{SiO}_{2}\right)$ 을 무게 비에 맞게 넣고 초음파를 이용하여 1 시간 동안 분산시켜 분말이 용매에 균일하게 분포하도록 처리하였다[11]. $\mathrm{SiO}_{2}$ 가 분산 된 폴리머 용액에 $10 \%$ 의 경화제를 첨가하고 교반기로 혼 합하여 코팅에 사용하였다.

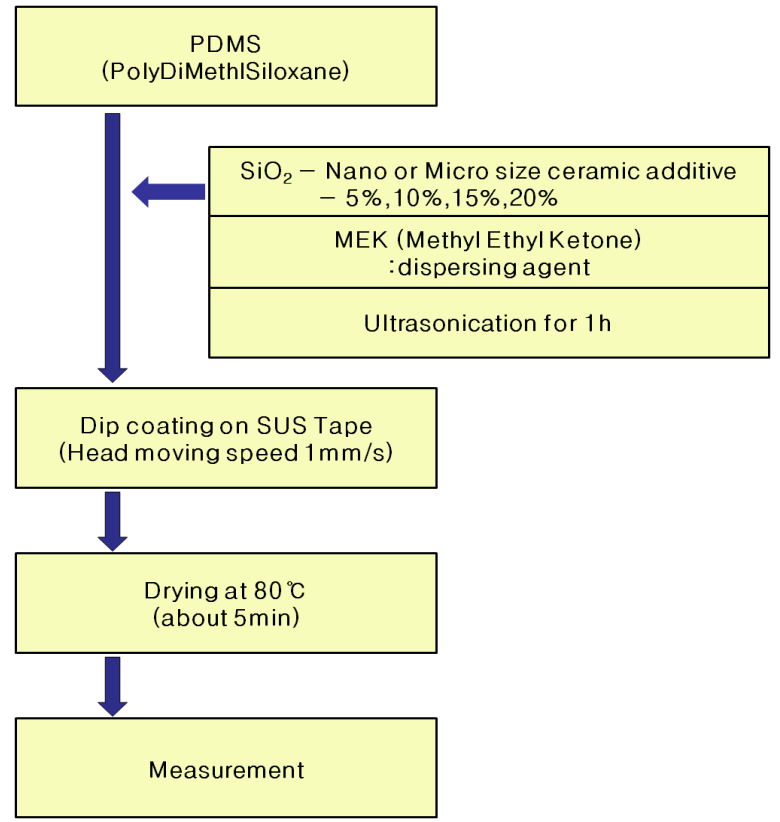

Fig. 1. Procedures for preparing and testing ceramic-polymer composite layer for electrical insulation of coated conductor.

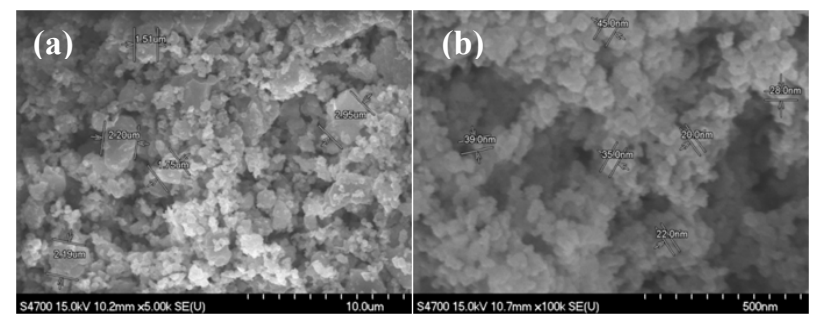

Fig. 2. SEM Morphology of $\mathrm{SiO}_{2}$ powder added to PDMS: (a)micro $\mathrm{SiO}_{2}(1-10 \mu \mathrm{m})$ (b) nano $\mathrm{SiO}_{2}(10-30 \mathrm{~nm})$.

$10 \mathrm{~mm}$ 폭의 SUS 테이프(SUS310)에 준비된 코팅용액 을 딥코팅 방법으로 코팅하였으며 이 때 SUS 테이프의 이 동속도는 $1 \mathrm{~mm} / \mathrm{s}$ 로 고정하였고, 1 회 코팅으로 $2-3 \mu \mathrm{m}$ 의 두께의 증착층이 형성되었다. 폴리머-세라믹 복합체를 코 팅한 SUS 테이프 샘플은 $80{ }^{\circ} \mathrm{C}$ 에서 10 분 동안 건조시켰다. 코팅과 건조과정을 1-5 회 반복하여 두께가 다른 시편을 제작하였고, 코팅된 시편을 절연파괴강도 측정기로 절연파 괴가 일어나는 전압을 측정하였다. 절연층의 두께는 알파스 텝으로 측정하였으며 절연파괴 실험은 실온에서 진행하였 다.

분말의 크기가 절연특성에 미치는 영향을 관찰하기 위해 nano- $\mathrm{SiO}_{2}$ (평균입도 $10-20 \mathrm{~nm}$ ) 와 micro- $\mathrm{SiO}_{2}$ (평균 입도 $1-5 \mu \mathrm{m})$ 두 가지의 $\mathrm{SiO}_{2}$ 분말을 첨가제로 사용하였으 며 Fig.2 는 이들의 형태를 SEM 으로 관찰한 결과이다. nano- $\mathrm{SiO}_{2}$ 는 전체적으로 수십 $\mathrm{nm}$ 크기의 입자가 고르게 분포된 형태를 보이며, micro- $\mathrm{SiO}_{2}$ 는 수 $\mu \mathrm{m}$ 크기의 분말 과 수십 $\mathrm{nm}$ 크기의 미세한 분말이 혼합되어 큰 입자에 미세 한 분말들이 붙어 있는 모양을 보이고 있다.

각각의 분말을 $5 \%, 10 \%, 15 \%, 20 \%$ 의 무게비로 $\mathrm{PDMS}$ 에 첨가하여 세라믹 입자의 형태와 함께 첨가되는 양 에 따른 절연특성과 접착력의 변화를 시험하였다. 


\section{RESULTS \& DISCUSSION}

\section{1. 절연 코팅층의 표면 미세조직}

Fig.3 은 PDMS 용액에 1-10 $\mu \mathrm{m}$ 크기의 micro- $\mathrm{SiO}_{2}$ 분말을 각각 무게비로 $5,10,15 \%$ 씩 분산시킨 전구용액으로 코팅한 표면을 $\mathrm{SEM}$ 으로 관찰한 결과이다. 첨가된 입자는 코팅층 내부에 포함되는 것 보다는 표면으로 돌출되어 분포하는 형태를 보이며 큰 분말들이 서로 뭉쳐서 부분적으로 밀집되게 관찰되며 분말이 박혀있거나 얹혀 있는 형태를 보인다. 분말의 첨가량이 증가할수록 표면에서 관찰되는 큰 입자의 수가 많아지며 작은 입자들은 잘 관찰되지 않는다. Fig.4 는 10-30 nm 크기의 nano- $\mathrm{SiO}_{2}$ 분말을 $5,10,15 \%$ 씩 분산시킨 전구용액으로 코팅한 표면을 관찰한 결과로서 마이크로 분말처럼 큰 입자가 표면근처에 편중되지 않고, PDMS 내에 균일하게 분산된 상태로 관찰된다.
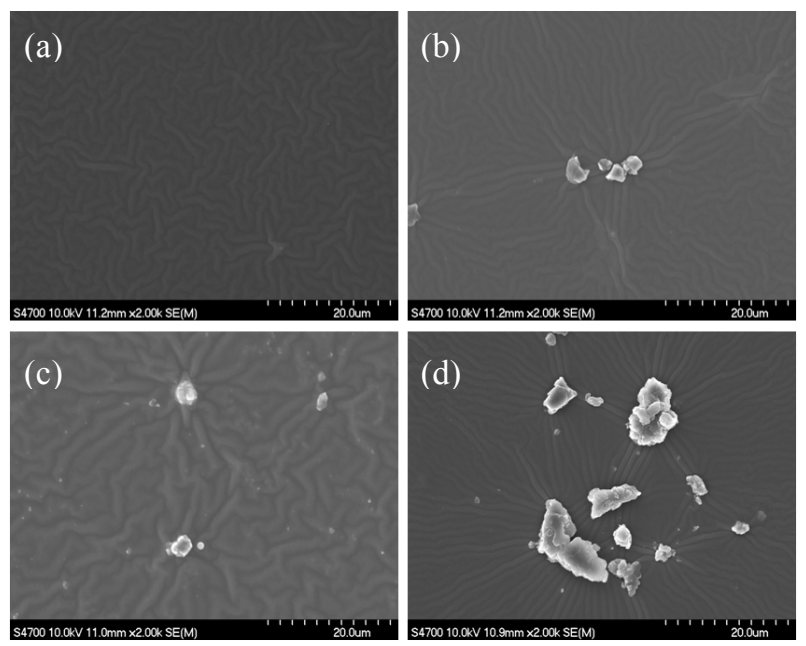

Fig. 3. Surface morphology of coated PDMS layer coated with micro $\mathrm{SiO}_{2}$ powder added precursor solution (a)pure PDMS (b) $5 \%$ micro- $\mathrm{SiO}_{2}$ (c) $10 \%$ micro-SiO 2 (d) $15 \%$ micro- $\mathrm{SiO}_{2}$.
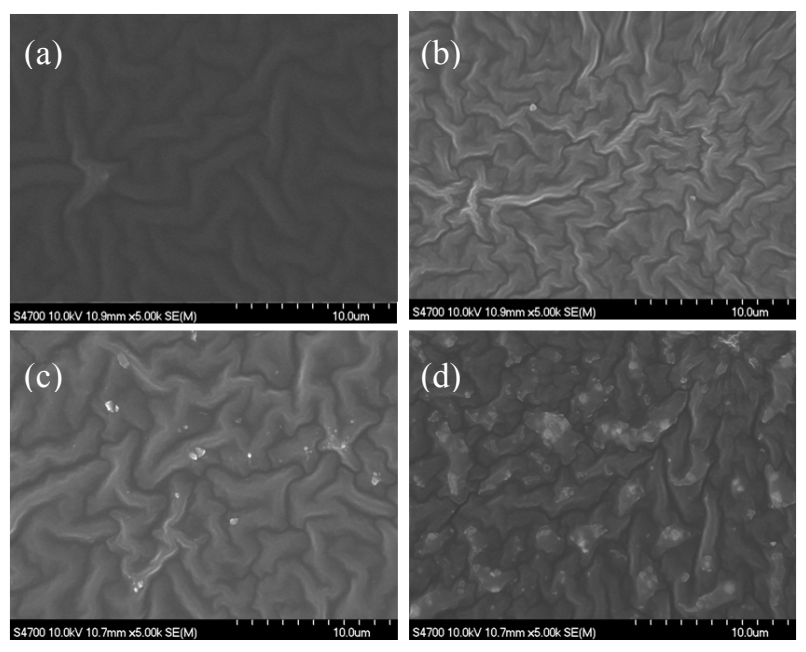

Fig. 4. Surface morphology of coated PDMS layer coated with nano $\mathrm{SiO}_{2}$ powder added precursor solution (a)pure PDMS (b)5 \% nano- $\mathrm{SiO}_{2}$ (c)10\% nano- $-\mathrm{SiO}_{2}$ (d)15\% nano- $\mathrm{SiO}_{2}$.

\section{2. 절연측의 접착성}

절연 코팅층이 효과적인 절연특성을 나타내기 위해서는 사용조건에서 초전도 선재의 금속표면과 강하게 접착되어 선재를 이용한 코일 가공시 떨어지지 않아야 하며 코일의 사용 중에도 분리되지 않아야 한다. 특히 초전도선재는 극저온에서 사용되므로 이 상태에서의 절연특성이 중요할 뿐 아니라 초전도 기기가 사용되지 않는 경우 상온으로 온도가 상승했다가 다시 냉각되는 과정에서 팽창과 수축이 반복되어 금속층과 절연 피복층의 열팽창계수의 차이에 따라 응력이 작용하여 분리되기 쉽다. 따라서 절연층이 코팅된 SUS tape 시편을 액체질소에 담궜다가 꺼내는 온도변화를 10 회 반복한 후 코팅층의 접착성을 측정하여 사용 환경에서의 접착력을 측정하였다. 접착력의 측정은 절연 피복층의 표면에 문구용 칼로 $2 \mathrm{~mm}$ 간격으로 격자모양의 흠집을 내고 접착 테이프를 부착 후 떼어내어 총 접착면적에서 몇 \% 의 피복층이 남아있는 지를 측정하여 평가하였다. 접착력이 적절한 수준인지를 확인 하는 Adhesion 테스트를 실시하였다.

Fig.5 는 이렇게 접착력을 시험한 결과로서 Fig.5(a)는 $\mathrm{SiO}_{2}$ 유전체가 첨가되지 않은 PDMS 코팅 시편이며, Fig.5 (b) 와 (c) 는 각각 nano- $-\mathrm{SiO}_{2}$ 와 micro- $-\mathrm{SiO}_{2}$ 분말이 $10 \%$ 첨가된 코팅층을 시험한 결과이다. Fig.5 (a) 와 (b)에 보인 것과 같이 순수한 $\mathrm{PDMS}$ 코팅층과 nano- $\mathrm{SiO}_{2}$ 를 첨가한 코팅층은 10 회의 온도변화 후에도 코팅층의 접착력이 잘 유지되어 접착력 시험에서 코팅표면이 떨어지지 않았다. 그 러나 PDMS 에 micro- $\mathrm{SiO}_{2}$ 분말이 첨가한 코팅층에 대한 결과는 온도변화 후에는 박리가 일어나지 않았고 접착력시 험을 진행한 결과 Fig.5(c) 에 보인 것과 같이 코팅층이 금 속층에서 쉽게 분리되어 대략 $86.5 \%$ 의 피복층이 남아있었 다. 이러한 결과는 micro- $\mathrm{SiO}_{2}$ 분말이 PDMS 내에 고루 분 산되지 않고 부분적으로 뭉쳐서 PDMS 와 금속층의 접촉면 적으로 줄이는 효과를 나타내어 그 부분의 접착력을 저하시 킨 때문으로 생각된다.

Fig.5(d)는 마이크로 분말을 첨가한 PDMS 를 코팅한 샘 플의 표면을 주사전자현미경 (SEM)으로 관찰한 결과이다. 특별히 응력을 가하지 않고 SUS 테이프에 폴리머-세라믹 복합체를 코팅 후 건조만으로 표면에 박리가 발생한 형태가 관찰되었다. 폴리머 내에 micro- $-\mathrm{SiO}_{2}$ 분말이 부분적으로 밀집된 부분에서 폴리머가 금속층과 접촉되지 못하여 접착 력을 감소시키는 형태를 나타내고 있다.
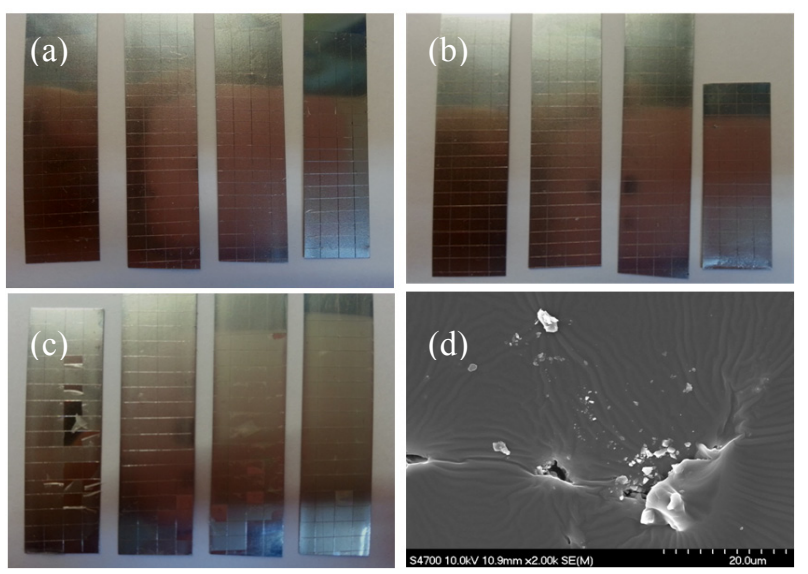

Fig. 5. Result of adhesion tests for (a)pure PDMS (b)10\% nano- $\mathrm{SiO}_{2}$ added PDMS (c)micro-SiO 2 added PDMS (d)SEM surface morphology of micro- $\mathrm{SiO}_{2}$ added PDMS layer. 


\section{3. 절연파괴강도}

절연파괴강도에 미치는 절연 피복층 두께의 영향을 알아 보기 위하여 코팅횟수를 달리하여 절연피복층의 두께를 조 절한 시편들의 절연파괴전압을 측정하였다. 절연파괴전압 을 측정할 때 전극으로는 절연층이 코팅된 SUS 테이프를 바 닥면의 평판전극으로 사용하고 윗면은 $3 \mathrm{~mm} * 3 \mathrm{~mm}$ 크기 의 구리평판을 평판전극으로 사용하였다.

Fig.6 은 $\mathrm{SiO}_{2}$ 유전체가 첨가되지 않은 PDMS 코팅층과 nano $-\mathrm{SiO}_{2}$ 와 micro- $\mathrm{SiO}_{2}$ 분말이 각각 $10 \%$ 첨가된 코팅 층의 두께에 따른 절연파괴 강도를 나타낸 것이다. 코팅층 의 두께가 $4 \mu \mathrm{m}$ 정도인 1 회 코팅한 시편의 절연파괴강도 는 거의 같은 값을 보이지만 코팅층의 두께가 증가함에 따 라 $\mathrm{SiO}_{2}$ 유전체가 첨가된 피복층들의 절연파괴강도가 더 높 게 나타나며 크기가 적은 nano- $\mathrm{SiO}_{2}$ 분말을 첨가한 경우가 절연파괴 전압에 더 큰 영향을 주는 결과를 보였다. 절연 코 팅층의 두께가 $12 \mu \mathrm{m}$ 인 경우를 비교할 때 micro- $\mathrm{SiO}_{2}$ 첨 가 코팅층은 순수 $\mathrm{PDMS}$ 층보다 $43 \%$ 의 절연파괴전압 증 가를 보였으나 nano- $\mathrm{SiO}_{2}$ 첨가 코팅층의 경우는 절연파괴 강도가 $129 \%$ 정도 향상된 결과를 나타내었다. 이런 결과는 micro- $\mathrm{SiO}_{2}$ 분말을 첨가하는 경우 입자들이 고르게 분산 되지 않고, 뭉쳐서 절연파괴강도를 높이는데 크게 기여하지

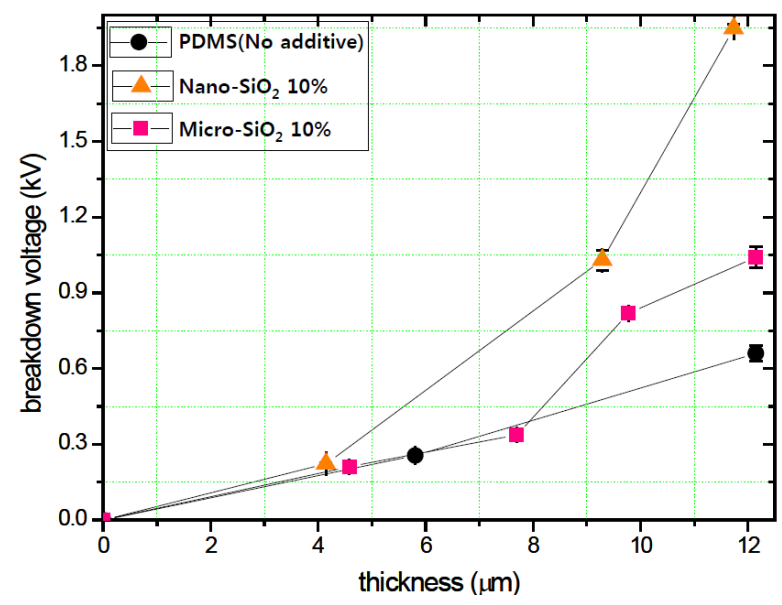

Fig. 6. Effect of additive size on electrical breakdown strength of ceramic added PDMS insulation coating layer.

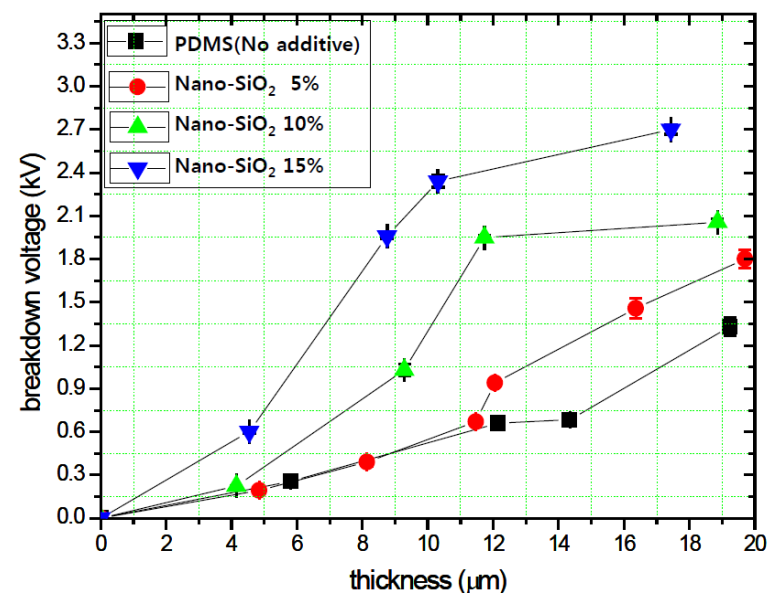

Fig. 7. Effect of additive concentration on electrical breakdown strength of nano- $\mathrm{SiO}_{2}$ added PDMS insulation coating layer on SUS tape.



Fig. 8. The micro structure of a Polymer-ceramic Composite.

못한 것으로 해석되며, 절연층의 접착성도 떨어뜨리므로 입 자크기가 작은 nano- $\mathrm{SiO}_{2}$ 분말을 첨가하는 것이 효과적으 로 절연파괴강도를 높이는 방법이라고 생각된다.

Fig. 7 은 PDMS 에 첨가하는 nano- $\mathrm{SiO}_{2}$ 분말의 함량에 따른 절연파괴강도 변화를 시험한 결과로서 첨가하는 nano $-\mathrm{SiO}_{2}$ 분말의 함량이 증가할수록 절연파괴강도가 증 가하는 경향을 나타낸다. 두께가 $18 \mu \mathrm{m}$ 일 때의 절연파괴 강도를 비교해 보면 PDMS 에 nano- $\mathrm{SiO}_{2}$ 분말을 $5 \%$ 첨가 한 복합체의 경우 분말을 첨가하지 않은 PDMS 용액으로 코 팅한 샘플보다 절연파괴강도가 약 $33 \%$ 정도 향상된 것을 확 인할 수 있고, $10 \%$ 를 첨가하게 되면 약 $65 \%$ 정도 향상된 결 과를 얻을 수 있다. 또한 $15 \%$ 의 분말을 첨가하게 되면 약 $125 \%$ 가까이 향상된 절연파괴 강도를 얻을 수 있었다. 하지 만 PDMS 용액에 nano- $\mathrm{SiO}_{2}$ 분말을 $20 \%$ 이상 첨가시에 는 PDMS 용액 내부의 분말간 거리가 가까워져서 폴리머간 연결이 끊어지게 되며 분말의 뭉침 현상이 심해지고 표면이 매끄럽게 코팅이 되지 않는 모습을 보였다. 이는 부분방전 을 초래하게 되므로 절연층으로 사용 할 수 없고 정확한 절 연파괴강도도 얻을 수 없으므로 nano- $\mathrm{SiO}_{2}$ 분말을 $20 \%$ 이 상 첨가하는 실험은 진행하지 않았다.

Fig.8 은 기본 폴리머에 세라믹 분말을 첨가했을 때 형성 되는 복합재료의 내부구조를 도식화 한 그림으로 세라믹 분 말이 복합체의 내부공간을 채워서 밀도를 높이고 유전상수 를 높이는 원리를 나타낸 그림이다. 본 연구에서 사용된 폴 리머-세라믹 복합체는 그림과 같이 고유전율, 저손실의 세 라믹 분말이 폴리머용액에 분산되어 용액의 유전율이 증가 하는 효과를 주었다. 또한 이를 통해 세라믹분말의 함유량 이 증가할수록 용액 내부에서 유전율이 높은 세라믹 분말의 부피비율이 증가하여 절연파괴강도가 증가하는 효과를 보 이는 것으로 생각된다.

본 실험에서는 절연특성을 상온에서 측정하였는데 극저온 에서의 냉각상태에서 열적 수축에 의해 첨가된 세라믹 분말 과 폴리머의 경계부에서 균열이나 틈새가 발생하면 절연특 성이 저하될 수 있을 것이나 반복적인 온도의 냉각과 회복 후 접착력의 감소가 없었던 것으로 미루어 보아 세라믹 분말과 폴리머 간의 경계면에서 균열이나 틈새가 발생하지 않을 것 으로 판단된다. 즉, $\mathrm{PDMS}$ 에 nano- $\mathrm{SiO}_{2}$ 분말을 첨가한 복 합체의 경우 첨가된 분말의 크기가 작아서 $\mathrm{PDMS}$ 와 nano $-\mathrm{SiO}_{2}$ 분말의 열팽창 차이가 균열을 일으킬 정도로 크 지 않으며 극저온에서의 절연특성도 상온에서와 같이 nano $-\mathrm{SiO}_{2}$ 분말의 첨가에 의하여 향상될 것으로 생각된다.

\section{CONCLUSION}

$2 \mathrm{G}$ 고온초전도 선재의 표면에 세라믹분말 $\left(\mathrm{SiO}_{2}\right)$ 과 폴리 머(PDMS) 의 복합재료박막을 초전도 선재표면에 코팅하여 
얇은 두께로 높은 절연내력을 가지는 절연층을 제조하기 위 한 연구에서 얻어진 결과는 다음과 같다.

(1) $\mathrm{PDMS}$ 용액에 $\mathrm{SiO}_{2}$ 분말을 첨가하면 $\mathrm{SiO}_{2}$ 의 높은 유전율에 의하여 $\mathrm{PDMS}$ 층의 절연내력이 증가한다.

(2) 분말크기가 큰 micro- $\mathrm{SiO}_{2}$ 분말을 첨가하면 분포가 균일하지 않고, 분말부에서 $\mathrm{PDMS}$ 층과 선재 표면과의 접착성을 떨어뜨려 효과적인 절연층을 제조하기 어렵다.

(3) nano $-\mathrm{SiO}_{2}$ 분말의 경우 PDMS 층 내에 균일하게 분포하여 접착력의 감소없이 절연내력이 증가하여 $15 \%$ 증가시 $125 \%$ 의 절연강도 증가효과를 보이지만 그 이상의 첨가는 $\mathrm{PDMS}$ 층과의 접촉면적을 감소시켜 접착력이 떨어지는 현상을 보인다.

\section{ACKNOWLEDGMENT}

This work was supported by Nano-Convergence Foundation funded by the Ministry of Science, ICT \& Future Planning (MSIP,Korea) \& the Ministry of Trade, Industry \& Energy (MOTIE, Korea).

\section{EXAMPLE REFERENCES}

[1] Sang-Heon Lee, "Electromagnetic Characteristics of Superconducting Ceramics for Electrical Power Devices", The Transactions of the Korean Institute of Electrical Engineers, vol. 60, no. 2, pp.349 - 351, 2011.

[2] H. S. Sin, M. Dedicatoria, "Research Trends of electric-mechanical charactristics of 2G HTS", Ceramist, vol 15, no. 6, pp.33 - 41, 2012.

[3] T. G. Park, S. H. lee, W. J. Shin, J. K. Seong, S. H. Oh, J. S. Hwang, B. W. Lee, "Study on the Comparison between DC and AC for Breakdown Characteristics of Dielectric Insulating Materials for Design of HTS Transformer in Cryogenic Environment", The Korean Institute of Electrical Engineers, p.1564-1565, 2011.

[4] H. G. Cheon, J. H. Choi, M. S. Pang, S. H. Kim, "The insulation design of HTS transformer and bushing", Superconductivity and cryogenics, vol.12, no. 3, pp.12-15, 2010.

[5] H. J. Bae, "Trend of technology of insulation material of wire"

[6] K. H. Cho, D. C. Woo, H. D. Nam, H. Y. Lee, "Effect of Pore Size and Porosity on Electrical Breakdown Behaviors of BaTiO3 Ceramics", The Journal of the Korean Institute of Electrical and Electronic Material Engineers, vol.10, no. 3, pp.255-261,1997.

[7] Teresa Oh, "Correlation between the Thickness and Variation of Dielectric Conatant on SiOC thin Film", International journal of KIMICS, vol. 13, no.12, pp2505-2510, 연도.

[8] H. J. Cho, D. Jung, "Syntheses and Characterizations of Polymer-Ceramic Composites Having Increased Hydrophilicity, Air-Permeability, and Anti-Fungal Property", Korean Chemical Society, vol.54, no.1, pp.137-141, 2010.

[9] M. S. Park, M. P. Chun, J. H. Cho, J. H. Nam, B. H. Choi and S $\mathrm{Nahm}$, "Preparation and Dielectric Properties of Ceramic(BNT)-Polymer(LCP) Composite", Journal of the Korean Institute of Electrical and Electronic Material Engineers, vol. 22, p.935, November 2009.

[10] J. Y. Park and M. G. Allen, "Packaging-compatible High Q Microinductors and Microfilters for Wireless Applications", IEEE Trans. Adv. Package., 22 [2] 207-13, 1999.

[11] Jae-Jun Park, Ju-Ho Kim and Young-Bum Park, "Breakdown Characteristics of Epoxy-Organoclay_10A Nanocomposites for Power Ultrasonic Application", The Transactions of the Korean Institute of Electrical Engineers, 1340-1342, July 2008. 